Farum

Sociológico

\section{Forum Sociológico}

Série II

$35 \mid 2019$

Arte urbana: Contextos, tendências e desafios

\title{
As smart-cities e a arte pública. $O$ contributo da curadoria no universo digital
}

Smart-cities and public art. The contribution of curatorship in the digital universe

Catarina Valente e Helena Elias

\section{CpenEdition}

\section{Journals}

Edição electrónica

URL: https://journals.openedition.org/sociologico/8105

DOI: 10.4000/sociologico.8105

ISSN: $2182-7427$

Editora

CICS.NOVA - Centro Interdisciplinar de Ciências Sociais da Universidade Nova de Lisboa

Edição impressa

Paginação: 37-39

ISSN: 0872-8380

\section{Refêrencia eletrónica}

Catarina Valente e Helena Elias, «As smart-cities e a arte pública. O contributo da curadoria no universo digital», Forum Sociológico [Online], 35 | 2019, posto online no dia 11 dezembro 2019, consultado o 29 março 2022. URL: http://journals.openedition.org/sociologico/8105 ; DOI: https:// doi.org/10.4000/sociologico.8105 


\title{
AS SMART-CITIES E A ARTE PÚBLICA. O CONTRIBUTO DA CURADORIA NO UNIVERSO DIGITAL
}

\section{SMART-CITIES AND PUBLIC ART. THE CONTRIBUTION OF CURATORSHIP IN THE DIGITAL UNIVERSE}

\author{
Catarina Valente \\ Universidade Lusófona de Humanidades e Tecnologias | CICANT - Center for Research in Applied Communication, Culture, \\ and New Technologies
}

\section{Helena Elias}

Faculdade de Belas-Artes da Universidade de Lisboa, VICARTE - Glass and Ceramic for the Arts

\section{Resumo}

Assistimos à transição para uma paisagem urbana mediatizada. O impacto visual da arte pública alterou os padrões de consumo. As smart-cities reconheceram a arte pública como um fenómeno dinamizador do tecido urbano. A sua integração na cultura visual sublinha a importância da arte pública no contexto urbano e nos processos de significação simbólica. A curadoria promove uma mediação mais eficaz entre as instituições, a comunidade artística e os públicos das cidades. No entanto, as aplicações móveis que exploram as produções murais não aprofundam os conteúdos fornecidos ao utilizador. A curadoria digital enriquece a produção destes conteúdos e oferece estratégias que dialogam com as infraestruturas físicas e virtuais das cidades. $O$ presente artigo apoia-se num modelo de investigação-ação das potencialidades da arte pública, contribuindo para o seu posicionamento nas instâncias física e virtual e para a evolução dos modelos de participação e de interação com as audiências, enquanto discute a importância da curadoria para a compreensão e legitimação dos processos artísticos inerentes à produção da arte no espaço público.

Palavras-chave: arte pública, smart-city, curadoria digital, cultura visual

\begin{abstract}
We are witnessing the transition to a mediatized urban landscape. The visual impact of public art changed the consumption patterns. The smart-cities recognized public art as a dynamic phenomenon of the urban fabric. Its integration in the visual culture underlines the importance of public art in the urban context and in the processes of symbolic signification. The curatorship promotes a more efficient mediation between the institutions, the artistic community and the publics of the cities. Nevertheless, the mobile applications exploring mural productions do not deepen the contents delivered to the user. Digital curatorship enriches the production of these contents and offers strategies that dialog with the physical and virtual infrastructures of cities. This article is based on the model of action-research towards the potentialities of public art, contributing to its positioning in the physical and virtual instances and to the evolution of the models of participation and interaction with the audiences, while discussing the importance of curatorship to the comprehension and legitimating of the artistic processes inherent to the production of art in the public space.
\end{abstract}

Keywords: public art, smart-city, digital curatorship, visual culture 


\section{Introdução}

O presente artigo divide-se em seis temáticas principais. Numa primeira instância, aborda-se a institucionalização da arte pública, ou seja, o crescente interesse por parte das entidades públicas e privadas pela expressão artística pública e pelos seus intervenientes. De seguida, introduz-se o conceito de smart-city e a sua relação com a arte pública, discutindo-se a interferência tecnológica na interação e na fruição da arte no espaço público. Por outro lado, discute-se a produção de conteúdos e a mediatização da prática da arte pública, refletindo-se sobre a utilização desta expressão artística por parte das aplicações móveis e a sua popularidade nos média. Apresenta-se, igualmente, o conceito de curadoria, com referência a diferentes posicionamentos teóricos, com os quais as autoras do presente artigo se relacionam, bem como o de digitalização da arte pública, na medida em que assistimos à transposição dos conteúdos visuais e escritos da prática para a dimensão digital, por via dos dispositivos tecnológicos e das plataformas de interação digital. Por fim, apresenta-se o estudo de caso, capítulo no qual se refere a cidade da Amadora como modelo representativo e de continuidade do legado da arte pública em Portugal. A metodologia adotada ao longo da presente investigação relaciona-se com a observação participante, sobretudo no que diz respeito à curadoria e à sua relação com a arte pública. O posicionamento das autoras sobre este campo de estudo advém da prática de ambas, nomeadamente através dos diferentes modelos experimentais que tiveram a oportunidade de testar, tanto ao nível científico como empírico, através de oficinas, festivais, exposições e outros contextos curatoriais. Assim, a investigação conduzida ao longo do presente artigo baseia-se na participação em projetos científicos e curatoriais que implicaram um perfil de investigação-ação (Lewin, 1946; Busch, 2009). Deste modo, o processo de recolha de dados desenvolveu-se a partir do registo fotográfico, do contacto com os agentes participantes, entre artistas, curadores e teóricos, da auscultação dos públicos participantes, de forma direta ou indiretamente, e da definição de ferramentas para testar estratégias curatoriais e de sensibilização.

\section{A institucionalização da arte pública}

A arte pública assume-se como um fenómeno que atrai diferentes tipos de audiências. Contudo, a opinião sobre as intervenções artísticas urbanas nem sempre é consensual. Práticas como o graffiti foram, desde logo, denominadas como um tipo de vandalismo ou um fenómeno invasor no espaço público e para o senso comum "uma linguagem hermética" (Campos, 2007, p. 249) desprovida de conteúdo crítico. Mais tarde, com a institucionalização da prática e o seu incentivo em contextos de exclusão social, o graffiti assumiu uma nova trajetória, possibilitada, sobretudo, pela popularidade dos seus autores e pelo impacto das suas narrativas visuais. De acordo com Ricardo Campos, o território urbano "é disputado por diferentes agentes, individuais e coletivos, que procuram marcar a sua presença, passar a sua mensagem" (Campos, 2007, p. 249). No caso do graffiti, estas disputas refletem-se no comportamento dos seus intervenientes e, sobretudo, na forma como interagem com o meio urbano.

Em Portugal, a institucionalização da arte pública ter-se-á iniciado com a criação da GAU (Galeria de Arte Urbana), organismo da Câmara Municipal de Lisboa, que viu no Bairro Alto e no seu elevado acervo de graffiti, uma oportunidade de regulamentar a prática, enquadrando--a em momentos específicos de intervenção local. Este posicionamento da Câmara de Lisboa influenciou outros organismos locais na procura da institucionalização do graffiti, como estratégia de controlo da prática, até à época realizada, sobretudo, em regime ilegal e não-sancionado. Para tal, aumentou-se, gradualmente, a escala das intervenções, seguindo-se outros modelos europeus e norte-americanos, numa tentativa de impactar as comunidades urbanas e de popularizar a prática. Estes modelos baseiam-se, principalmente, nos atributos físicos de determinada localização (Kwon, 2002). Neste sentido, procura-se criar iniciativas, em formato festival, que situam as intervenções numa determinada localização, com uma duração definida. Estes formatos contribuem para uma rápida transformação do lugar, sobretudo quando se trata de um espaço abandonado ou em visível estado de deterioração.

Se, numa primeira fase, estas intervenções em larga escala foram um teste à adesão das audiências, atualmente, estas multiplicam-se um pouco por todo o país, constituindo-se como referências da paisagem urbana das cidades portuguesas. Deste modo, a arte pública afirma-se, simultaneamente, como uma estratégia popular e populista, cujo contributo recai, sobretudo, na redução das assimetrias sociais e na harmonização da paisagem urbana. A arte pública assumiu--se, igualmente, como um fator integrador e impulsionador do dinamismo local, atraindo a fixação de indústrias criativas nos territórios urbanos, motivadas pelo impacto desta manifestação nas cidades e pela criação de oportunidades de exploração desta prática. Estas indústrias estimularam a criação de ferramentas de interação com as cidades, principalmente, com a integração da tecnologia na fruição urbana. 
O conceito de smart-city e a relação com a arte pública

Neste contexto, surge o conceito de smart-city. Ainda que consista num fenómeno recente, a smart-city assume-se como uma resposta ao rápido crescimento demográfico e urbanístico das cidades contemporâneas. A sustentabilidade das cidades é, hoje, evidenciada pela constituição de redes de parcerias, provenientes de diferentes áreas do conhecimento, com predomínio na tecnológica. Estes parceiros dispõem-se a reconfigurar o território, à mercê das exigências dos seus utilizadores, das instituições e da estrutura política. A mediação entre estes agentes de poder afirmou-se fundamental para fazer face aos desafios colocados pela globalização e pelos fluxos migratórios. De acordo com Paskaleva, as smart-cities utilizam as tecnologias digitais para serem socialmente inclusivas, promover a boa governabilidade e criar melhores serviços, que melhorem a qualidade de vida dos seus cidadãos, com um olhar para a sustentabilidade e a competitividade a longo prazo (Paskaleva, 2013). Estas cidades baseiam-se em fortes redes locais e, por isso, são responsáveis por um clima de inovação que vê na criatividade e na arte ferramentas para estimular a economia e a competitividade (Hall, 1998).

Este novo enquadramento contaminou a prática artística e, por este motivo, assistimos ao nascimento de uma nova cartografia da arte, por efeito da globalização (Weibel, 2013). As novas tecnologias servem como ferramentas que possibilitam a agilização destes processos e a aproximação do cidadão ao espaço público, constituindo-se como elementos dinamizadores da chamada economia urbana. Neste contexto, promovem-se interfaces entre as realidades virtual e física que estimulam a interação humana com a cidade. No contexto das indústrias criativas, iniciam-se os primeiros incentivos à produção multidisciplinar, com o envolvimento das áreas tecnológica e criativa, no sentido de se desenvolverem produtos inovadores, que permitam fruir a cidade de uma forma mais dinâmica e sensorial. Surgem as incubadoras e as start-ups como formatos de empreendedorismo jovem, destinados ao desenvolvimento de ideias, muitas delas provenientes de investigações académicas. Criam-se projetos-piloto de inovação urbana que atraem o investimento das autarquias locais pelas oportunidades de dinamismo das cidades. Ainda neste âmbito, iniciam-se as primeiras parcerias entre as áreas criativas, nomeadamente: a arte, o design, a publicidade, o marketing e a tecnologia. Introduzem-se, gradualmente, os dispositivos mediáticos nos territórios e nas dinâmicas sociais urbanas. De acordo com Peter Weibel, o novo paradigma da arte do século xxi é a web global, sobretudo, com a revolução da Web 2.0, ou seja, o acesso a todos os média em qualquer circunstância, o que contribuiu para tornar a experiência mediática um fenómeno universal (Weibel, 2013, p. 25). Weibel designa este paradigma por condição pós-medial, ou seja, a equivalência entre todos os média e a sua fusão (Weibel, 2013, p. 25).

$\mathrm{Na}$ arte, este fenómeno corresponde à utilização dos média na criação, no processo e no resultado enquanto ferramentas de aperfeiçoamento da expressão e da disseminação artística. Nesta conjuntura, as audiências são convidadas a interagir com estes mecanismos, introduzindo-se novas trocas comunicacionais e formatos de interação com a arte. A arte pública surge como uma força motriz, apta ao fortalecimento do laço social e da relação do indivíduo com o território. A arte pública insere-se na smart-city como um instrumento de inclusão social e de combate ao estigma, sobretudo se considerarmos os projetos desenvolvidos na periferia da Grande Lisboa e do Grande Porto. Por outro lado, a arte pública afirma-se como fenómeno mediático e de atração turística para a "regeneração económica" (Remesar, 2005, p. 07), fatores que atraem o investimento por parte de organismos locais do interior do país. Neste contexto, parece difícil distinguir entre a arte pública que se assume como prática artística ou como uma estratégia de propaganda (Remesar, 2005). Entre os investimentos público e privado, a arte pública parece declarar-se como uma forma de afirmação de uma imagem, que poderá ser de origem política, comercial ou turística. Ainda que utilizada, frequentemente, como estratégia publicitária por parte de marcas e empresas privadas, o investimento na arte pública em Portugal assume-se mais elevado no setor público, devido, sobretudo, aos apoios internacionais nas áreas da inclusão social e do desenvolvimento comunitário.

Tendencialmente, no território português, os projetos são desenvolvidos mediante apoios públicos, apesar de realizados em parceria com organismos privados. Vejam-se as parcerias entre a empresa Mistaker Maker, coorganizadora dos festivais Muraliza, Wool Fest ou ESTAU, e os municípios de Cascais, Covilhã e Estarreja, respetivamente. As marcas e entidades privadas procuram desenvolver as suas próprias ações, enquadradas na sua estrutura de promoção e consolidação da imagem institucional. Por este motivo, uma amostra significativa dos projetos realizados em Portugal apresenta uma rede de patrocinadores, cuja oferta recai na atribuição de bens ou produtos. Ou seja, as empresas canalizam os recursos para um determinado fim, rejeitando-se a aplicação de um montante financeiro. Assim, resta aos organismos públicos a concessão de uma verba destinada ao desenvolvimento destes projetos. 


\section{A produção de conteúdos e a mediatização da prática}

A ausência de reconhecimento da arte pública como prática artística, sobretudo pela sua condição urbana e o seu carácter efémero, condicionou a produção de conteúdos de reflexão sobre esta instância. Por este motivo, a prática carece de sensibilização e de investigação nos âmbitos académico, artístico e cultural. Apesar de se constituir como uma atração turística, a arte pública necessita dos enquadramentos institucional e artístico, estando, por isso, o seu posicionamento fragilizado no mundo da arte. 0 panorama global das plataformas dedicadas à promoção da arte pública restringe-se à georreferenciação das obras ou à menção aos artistas executantes. A título de exemplo, vejam-se os mapeamentos constantes das plataformas de divulgação de projetos de arte pública, tanto a nível europeu como global. A ênfase atribuída à localização evidencia a tentativa de tornar a obra um produto turístico, visto que, no caso português, proliferam os roteiros dedicados à exploração e à fruição da arte pública. No seguimento desta premissa, importa introduzir a componente digital. Estes roteiros temáticos contribuem para aumentar o número de seguidores destas expressões. Habitualmente, estes visitantes interagem com a obra mediante o registo, através do seu dispositivo móvel, do mural ou da instalação escultórica pública que estão a observar e que partilham nas suas redes sociais. Esta dinâmica reforça o envolvimento por parte dos públicos em relação à arte pública, sobretudo se o utilizador referenciar o autor ou a entidade promotora que possibilitou aquela intervenção.
Neste contexto, os processos, as materialidades, as técnicas, os contextos e os conceitos são obliterados, visto que a ênfase recai no impacto e na popularidade da narrativa visual. Deste modo, a aposta por parte destas instituições assenta, sobretudo, no potencial valor comercial destas obras. Veja-se o caso de Banksy e da especulação em torno da sua produção artística.

Pese-se a criação do museu Moco, na cidade de Amesterdão. Situado na praça dos museus, este museu de arte contemporânea foi impulsionado por um casal de negociantes de arte, Lionel e Kim Logchies, que, aproveitando a sua vasta rede de contactos no mercado artístico, apresentam um acervo de obras provenientes de colecionadores privados, através de um núcleo de exposições temporárias. Uma percentagem significativa deste acervo é dedicada a Banksy. Na brochura do museu, pode ler-se que Banksy não sancionou a exposição, ou seja, a mostra não foi autorizada pelo artista, apesar de, segundo a instituição, o próprio, até à data, não ter procedido ao seu impedimento. Em cada sala dedicada a Banksy, observamos a atribuição de um tema, intimamente relacionado com as obras apresentadas. Por outro lado, verificamos que a maioria deste acervo foi retirado, deliberadamente, do espaço público, apresentando-se ainda vestígios dessa extração, sobretudo fragmentos do suporte original.

A transposição das obras do seu local de origem para contextos como o museu Moco revela diferentes estratégias de apropriação dos trabalhos artísticos, realizados em contexto urbano: 1) a extração mecânica, em que a obra de arte pública

Figura $1 \triangleright$ Printscreen do mapa de intervenções da plataforma Underdogs. É apresentado um mapa com a localização de cada um dos murais, a data, a menção ao seu autor e uma ou mais fotografias da intervenção
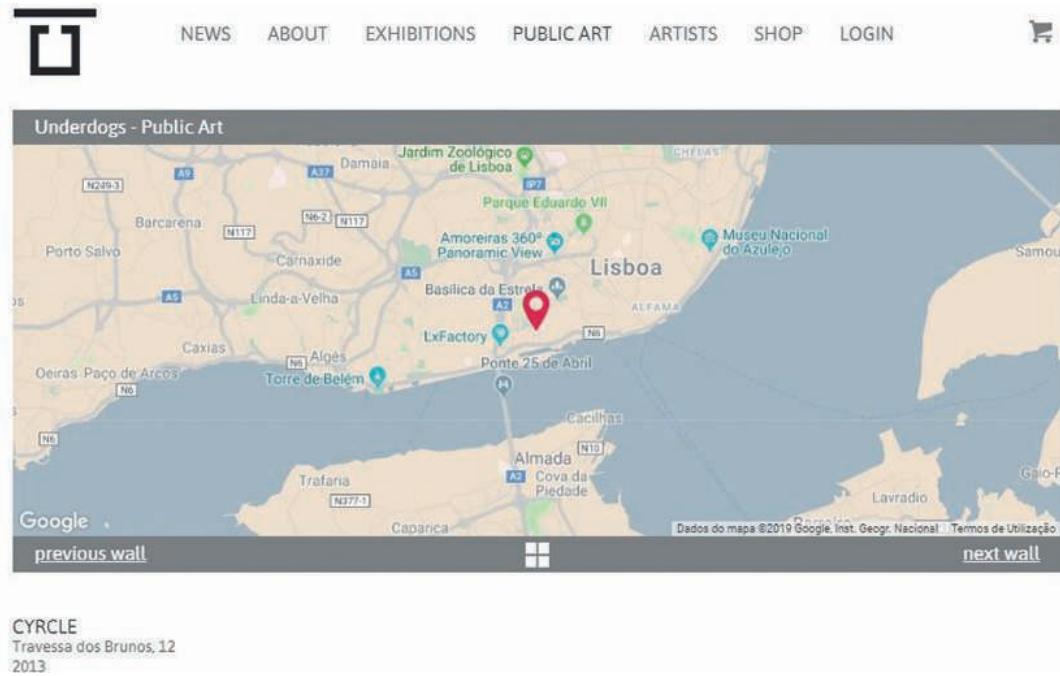

Fonte: https://www.under-dogs.net 
Figura $2 \triangleright$ Laugh now but one day we'll be in charge. Mural de Banksy retirado de um muro em Bristol, agora parte do acervo da exposição dedicada ao artista no Moco Museum, Amesterdão

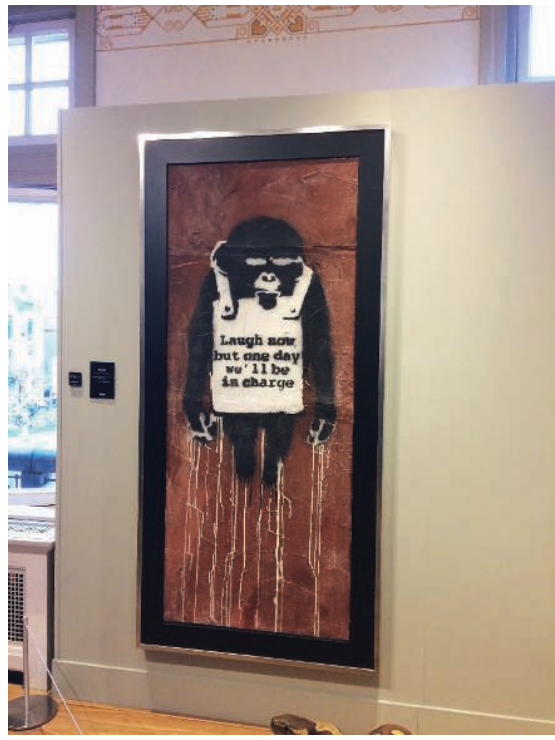

Fonte: Autoras.

é retirada mediante a utilização de um equipamento de extração, habitualmente sem o consentimento do autor; 2) a apropriação por via da documentação, ou seja, as coberturas fotográfica e vídeo da obra e a sua integração no acervo expositivo como objeto artístico isento de direitos de autor; 3) a apropriação por via da reprodução, que diz respeito à venda de merchandising que reproduz a obra em série.

Os aspetos identificados corroboram a prevalência de uma rede de capital social institucionalizada e baseada no reconhecimento mútuo (Bourdieu \& Wacquant, 1992). No caso da arte pública, esta rede é, atualmente, composta pela instituição, o mediador, o artista e a audiência. Contudo, e no seguimento da popularidade recente desta manifestação, o promotor afirmou-se como uma figura proeminente na atribuição de valor comercial aos objetos artísticos públicos. Isto porque os artistas constataram a necessidade de encontrar um agente que os posicionasse neste mercado, face ao aumento da procura. A compra de obras de arte pública por parte de leiloeiras e colecionadores privados é uma realidade assente na especulação destes trabalhos, com base no impacto visual que os mesmos exercem nas paisagens das cidades. Por este motivo, as cidades já não são vistas como paisagens de produção, mas sim como paisagens de consumo (Zukin, 1991).

\section{O conceito de curadoria e a digitalização da arte pública}

O conceito de curadoria adquiriu uma maior ênfase a partir da década de 1960, com o surgimento da arte conceptual e do chamado designer de exposições. Entregues a elites culturais, as galerias acolhiam, sobretudo, obras provenientes das coleções dos seus membros. Com o aparecimento da curadoria independente na década de 1960, o mundo da arte introduziu novos estilos e formatos inovadores de interação e exposição dos objetos. A partir deste momento, estavam reunidas as condições para a emergência de um modelo de curadoria contemporânea, cuja grande aposta recaiu na educação e sensibilização dos públicos, através da construção de novos modelos de interação e participação. De acordo com Paul O'Neill e Mick Wilson, os "formatos educacionais, os métodos, os programas, os modelos, os termos, os processos e os procedimentos tornaram-se pervasivos tanto nas práticas curatoriais como na produção da arte contemporânea e no seu enquadramento crítico" (O’Neill \& Wilson, 2010, p. 12). Por este motivo, cada vez mais, a curadoria opera como uma "prática educacional expandida" (O'Neill \& Wilson, 2010, p. 12). Ou seja, a curadoria almeja contemplar a educação como estratégia de aproximação dos públicos aos conteúdos expositivos. Neste contexto, surgem as primeiras exposições com o enfoque nos conceitos, nos processos e nos contextos de produção. Os limites expandem-se e o espaço público assume-se como a continuidade do museu. A escala dos objetos artísticos aumenta, como no caso da Land Art e, mais tarde, da arte pública, com as instalações escultóricas e os murais em larga escala. Cher Krause Knight considera que os trabalhos da arte pública foram concebidos para grandes audiências e posicionados para atrair a sua atenção, numa tentativa de providenciar "experiências estéticas que edificassem, comemorassem, ou entretivessem", sendo que as suas mensagens deveriam ser "compreensíveis pelas audiências generalizadas" (Knight, 2008, p. 22). Estes critérios estão na génese da criação do programa de arte pública "1\% para a Arte" (1978), instituído pelo governo norte-americano.

A curadoria de arte pública emerge como uma resposta à institucionalização da prática e à necessidade de mediação entre as instituições, os artistas e os públicos. Com a evolução tecnológica, a curadoria transferiu-se para outras instâncias, face à transposição da arte pública para o universo virtual. A constituição de arquivos e galerias virtuais de exposição e exploração da prática não acompanhou a produção de conteúdos de reflexão. Como tal, a divulgação da arte pública limitou-se à menção da autoria e do objeto, ausentes de contexto e de fontes conceptuais. Este enquadramento originou novos 
formatos de disseminação das obras, uma vez que a sua circulação nas plataformas digitais se processa de forma instantânea e liberalizada. Por este motivo, o mural foi convertido em produto, podendo ser consumido, independentemente da origem ou creditação.

Os direitos de autor não estão consagrados nestas plataformas, o que prejudica a legitimidade da autoria e dos contextos de produção. De acordo com Ricardo Campos, Inês Pereira e José Alberto Simões, devido à multiplicação das redes sociais, "os inputs informativos são muitos e, por vezes, não favorecem uma avaliação mais densa/ detalhada da informação, nomeadamente no que respeita à aferição da veracidade e fidedignidade dos seus conteúdos" (Campos, Pereira \& Simões, 2016, p. 42). Por este motivo, a obra de arte pública tem sido alvo de reprodução ilegal e de usurpação autoral. Frequentemente, nestas plataformas, o mural é divulgado como um produto mercantilizado, assumindo-se a entidade como autora da produção. A dissolução da autoria nos contextos digitais é uma problemática que resulta, sobretudo, da ausência de conteúdos fornecidos ao utilizador e do incentivo ao consumo instantâneo. A este propósito, pese-se a importância da curadoria digital no desenvolvimento de estratégias que dialogam com as infraestruturas físicas e virtuais das cidades.

O recurso à curadoria digital no contexto da arte pública teve por pressuposto a necessidade de digitalização dos murais, face à elevada amostra de registos nas cidades contemporâneas. Numa primeira fase, procedeu-se à digitalização dos registos e à constituição de arquivos virtuais, contrariando-se a génese efémera destas obras. Com a criação de arquivos digitais de arte pública, os registos extintos são recuperados e documentados virtualmente, prolongando-se a existência do mural no tempo. Contudo, verifica-se que estes arquivos carecem de informação contextual, nomeadamente a menção ao conceito, ao processo e ao contexto de produção. Nesta relação de ambiguidade, surge o curador, cujo contributo recai no aprofundamento dos conteúdos disponibilizados ao utilizador das plataformas. A sua função remete, igualmente, para a construção de significado, contribuindo, inclusive, para o estabelecimento de paralelismos com momentos de produção artística anteriores ou homólogos.

Atualmente, a curadoria no contexto digital desenvolve-se mediante duas instâncias, a imaterialidade e os sistemas de informação em rede (Krysa, 2006). Esta imaterialidade referida por Krysa remete-nos para o lugar do objeto artístico nestas redes, uma vez que a circulação da imagem não incorpora a sua génese empírica. No caso do mural, esta nova condição revela a perda da experiência sensorial, aspeto fundamental da interação com esta tipologia. Por outro lado, oculta-se, igualmente, a influência que as ações ambiental e social exercem na evolução do objeto e na sua relação com o lugar. Segundo Lucy Lippard, o lugar é uma "localização estratificada repleta de histórias humanas e de memórias" (Lippard, 1997, p. 07). Estas memórias e camadas de significado não são transpostas para a instância digital, devido ao seu carácter sensorial e à profundidade do seu enquadramento. Face ao imediatismo, instantaneidade e rapidez a que circula a informação em rede, o aprofundamento dos conteúdos, das memórias e do simbolismo do mural são aspetos habitualmente ausentes do arquivo digital. A função do curador passará por enriquecer estes acervos, oferecendo uma perspetiva crítica e reflexiva sobre a arte pública, através da produção de conteúdos. Por outro lado, o curador poderá definir um conjunto de critérios de seleção e de filtragem da informação. Esta matriz deverá impedir a disseminação de informação incorreta e desmistificar a condição da arte pública no mundo da arte, contribuindo para a credibilização da prática.

\section{A cidade da Amadora e o legado da arte pública}

A presença da arte pública na cidade da Amadora situa-se entre o período imediatamente a seguir ao 25 de Abril de 1974 e a atualidade. Numa primeira instância, a produção estava vocacionada, sobretudo, para a pintura mural de âmbito político-ideológico, motivada pela escola de muralismo do Partido Comunista Português (PCP), com uma mancha gráfica, predominantemente, de influência soviética. Habitualmente, os temas mais utilizados relacionavam-se com o estado da indústria, nomeadamente os sindicatos de trabalhadores das extintas Cometna e Sorefame, a marcação de greves ou a divulgação de eventos organizados pelo partido. $\mathrm{Na}$ Figura 3 encontra-se uma fotografia de um mural do PCP que exemplifica os aspetos referidos.

Figura $3 \triangleright$ Mural extinto, da autoria do PCP, localizado na freguesia da Falagueira

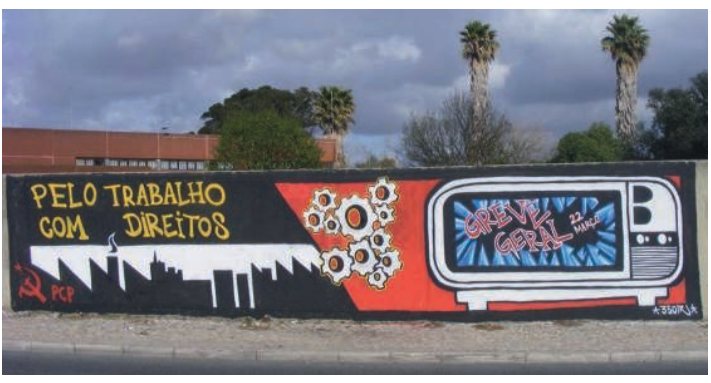

Fonte: Google Maps.

Gradualmente, esta intervenção política no espaço público foi abandonada, transitando-se para os mecanismos da publicidade. Procedeu-se à 
impressão e produção de materiais de divulgação, nomeadamente os outdoors, que veiculassem as mensagens ideológicas. A partir da década de 1990, iniciam-se as primeiras intervenções no contexto do graffiti, inspiradas, sobretudo, na cultura urbana norte-americana, destacando-se o artista Odeith, como um dos precursores da prática na cidade da Amadora. A partir deste período, constitui-se uma comunidade de artistas, provenientes da periferia da Grande Lisboa, com uma intensa ação pública nas linhas ferroviárias e nos principais eixos rodoviários, entre os quais Risko, Que, Slap, entre outros. Nestas interfaces, surgiam assinaturas em larga escala de elevada complexidade técnica e estética, cuja mancha gráfica predominante recaía na assinatura do pseudónimo do seu autor.

Ainda na década de 1990, e por forma a constituir um circuito de arte pública, motivado pelo núcleo de artistas e escultores locais, o município funda os chamados Simpósios Internacionais de Escultura em Ferro. Estes encontros visavam convidar artistas plásticos para se fixarem na cidade, por via de uma residência artística, durante a qual produziam peças escultóricas em ferro, para posterior instalação nos diferentes espaços públicos da cidade. Esta iniciativa contribuiu para a criação de um acervo de arte pública, do qual constam importantes referências da arte contemporânea nacional e internacional, entre os quais: João Limpinho, Laranjeira Santos, Herbert Nouwens ou Volker Schnüttgen. Este acervo tem vindo a ser atualizado mediante as diferentes abordagens artísticas aos espaços públicos da cidade, através de iniciativas de continuidade como a Mostra de Escultura ao Ar Livre, promovida pela Galeria Municipal Artur Bual.

Figura $4 \triangleright$ Cartaz do III Simpósio Internacional de Escultura em Ferro (1996)

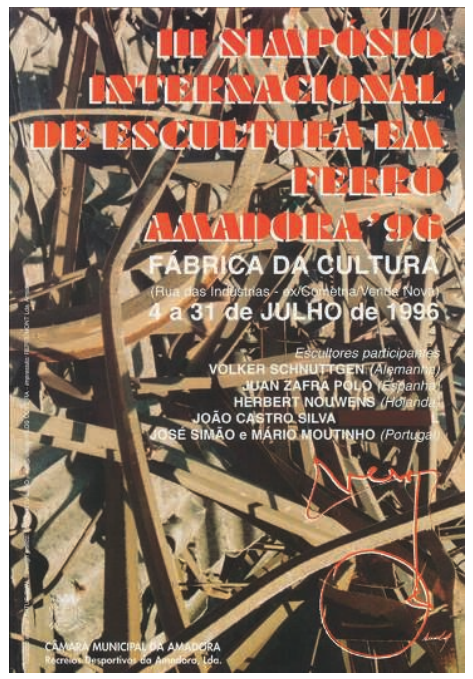

Fonte: Coleção Digital do Arquivo da Universidade de Aveiro (http://arquivo.sinbad.ua.pt).
Face ao elevado número de intervenções nos suportes urbanos da cidade da Amadora, importava compilar estes registos num formato de arquivo, que contemplasse, igualmente, murais já extintos. Com a crescente aposta municipal nas redes sociais e nos meios digitais como ferramentas de divulgação da atividade autárquica, sobressaiu a oportunidade de explorar o legado mural existente, por um lado, como uma estratégia de atenuação do estigma negativo associado à cidade, e, por outro, como um formato de potencialização da comunidade local, por via da arte e da sensibilização para a sua importância nos contextos educacional, recreativo, social e cultural. No seguimento desta premissa, surge o Mapa do Graffiti da Amadora, enquanto plataforma de documentação e divulgação dos registos murais do município e de fruição da arte pública, em contexto digital. Este projeto foi motivado pela presença de artistas locais que se destacavam na prática e que intervinham, com regularidade, no tecido urbano da cidade.

Os conteúdos apresentados contemplam o conceito, a autoria, a localização e o contexto de produção mural. O fator de inovação diz respeito à auscultação dos autores e à divulgação do seu testemunho, promovendo-se uma maior interatividade com o utilizador, patente na disseminação do processo de produção artística. Ao longo do tempo, alguns destes registos foram extintos, por ação do meio ambiente ou eventual destruição do suporte de acolhimento. Contudo, verifica-se que alguns exemplares sofrem a chamada sobreposição simbólica, ou seja, face à aparente deterioração da obra, o artista procede a uma nova intervenção sobre a anterior. Este fenómeno designa-se por palimpsesto. No caso da arte pública, a sobreposição de narrativas simbólicas parece responder à necessidade do artista de continuar o legado anterior e de incorrer, constantemente, na experimentação. A cidade da Amadora é um exemplo paradigmático de interação urbana por via artística, impulsionada pelas vivências sociais dos seus intervenientes. A presença constante da arte pública na cidade a partir da década de 1970 corrobora a necessidade de apropriação do espaço público, partindo-se, numa primeira fase, de um ímpeto coletivo, e, numa segunda fase, de demarcação individual por via da personificação do território. Esta tendência individual surge, por um lado, pelo elogio ao virtuosismo, ou seja, a constituição de uma hierarquia baseada na reputação do autor, e, por outro lado, pelo domínio das novas tecnologias na arte pública, pois a popularidade do artista é avaliada mediante o número de interações sociais que a sua obra adquire digitalmente. A dupla existência do mural, entre as dimensões real e virtual, parece desembocar na demanda por uma maior interatividade e pelo domínio da imagem. As narrativas em larga escala vão ao encontro da 
Figura $5 \triangleright$ Printscreen da plataforma Mapa do Graffiti na Amadora

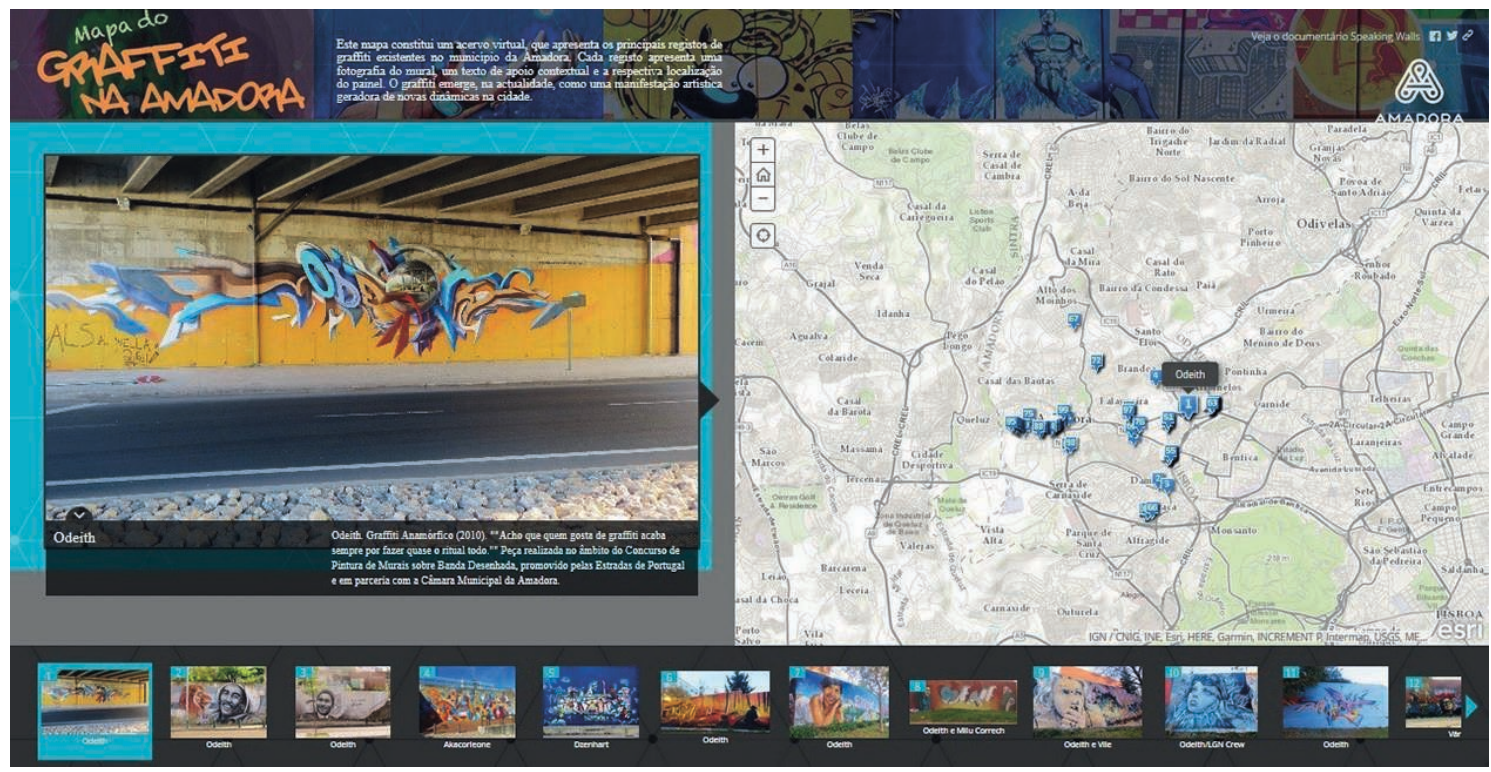

Fonte: Autoras.

espetacularização da arte pública. Isto é, a tendência para algo que Guy Debord designa por uma visão "objetificada" do mundo (Debord, 1970). A conversão do mural em objeto de consumo remete para a emergência da cidade-montra, onde a paisagem urbana se apresenta como um mostruário, composto por diferentes escalas visuais, sendo constantemente alvo de apropriações simbólicas.

\section{Considerações finais}

Atualmente, as cidades assumem-se como suportes da diversidade criativa, oferecendo ao indivíduo diferentes alternativas de contemplação e fruição artística. As narrativas respondem ao estado da arte e à impregnação desta instância pela cultura urbana, pelas novas tecnologias e pela economia criativa. Os murais são suportes que testemunham a história urbana e a evolução social e cultural. A curadoria surge enquanto elemento mediador na relação do indivíduo com o espaço público e no enquadramento da arte pública. Deste modo, a curadoria apresenta-se como um incentivo à reflexão e ao reconhecimento destas práticas nos espaços públicos contemporâneos. A transposição do objeto para a dimensão digital coloca um desafio à comunidade artística, na medida em que a sua circulação e consequente reprodutibilidade se tornam liberalizadas, devido à ausência de um enquadramento legal que contenha a disseminação das imagens. Assim, a curadoria pode constituir-se como um recurso válido no desenvolvimento de conteúdos de reflexão e de valorização da arte pública mural, uma vez que ofe- rece um contributo crítico ao posicionamento da arte pública no panorama atual. A curadoria facilita um conjunto de ferramentas estratégicas e técnicas que permitem legitimar e valorizar o enquadramento da arte pública, nomeadamente: a) estimular a reflexão científica sobre o objeto artístico representado; b) mediar a relação entre os diferentes agentes envolvidos na disseminação desta expressão artística; c) valorizar económica, artística e culturalmente esta prática, por via do núcleo de especialistas que integra a rede de capital social; d) enriquecer os conteúdos de disseminação desta instância artística.

Face ao legado de arte pública presente na cidade, a Amadora constitui um estudo de caso revelador da influência da prática artística na paisagem urbana e na disseminação das mensagens coletiva e individual. Enquanto espaço democrático por excelência, a rua afirma-se como um suporte atrativo para veicular conteúdos ideológicos e simbólicos que testemunham a herança histórica e social dos seus intervenientes. Na nova cidade contemporânea, as suas infraestruturas dividem-se entre as instâncias física e virtual e o disruptivo e o cânone, sendo que a memória parece constituir-se como o elemento de ligação entre ambas. A história das cidades é contada nas paredes, nos muros, nos sinais de trânsito ou nos pilares dos viadutos. As narrativas sobrepõem-se e revelam a evolução da apropriação humana dos espaços públicos. Este mosaico, tanto real como virtual, de memórias visuais é um fenómeno resultante da sociedade fragmentada, dispersa e, simultaneamente, em rede que evolui à medida do pulsar tecnológico. 


\section{Referências bibliográficas}

Bourdieu, P., \& Wacquant, L. J. D. (1992). An Invitation to Reflexive Sociology. Chicago: University of Chicago Press.

Busch, K. (2009). Artistic Research and the Poetics of Knowledge. Art\&Research: A Journal of Ideas, Contexts and Methods, v. 2., n. 2., 1-7.

Campos, R. (2007). Pintando a Cidade: Uma Abordagem Antropológica ao Graffiti Urbano (tese de doutoramento). Lisboa: Universidade Aberta.

Campos, R., Pereira, I., \& Simões, J. A. (2016). Ativismo Digital em Portugal: Um estudo exploratório. Sociologia, Problemas e Práticas, 82, 27-47.

Debord, G. (1970). Society of the Spectacle. Detroit: Black \& Red.

Hall, P. (1998). Cities in Civilization: Culture, Technology and Urban Order. Londres: Weidenfeld and Nicolson.

Knight, C. K. (2008). Public Art: Theory, Practice and Populism. Maldon: Wiley-Blackwell Publishing.

Krysa, J. (ed.) (2006). Curating Immateriality: The Work of the Curator in the Age of Network Systems. Londres: Autonomedia.
Kwon, M. (2002). One Place After Another: Site-Specific Art and Locational Identity. Cambridge: The MIT Press.

Lewin, K. (1946). Action research and minority problems. In G.W. Lewin (Ed.), Resolving Social Conflicts. Nova Iorque: Harper \& Row.

Lippard, L. (1997). The Lure of the Local: Senses of Place in a Multicentered Society. Nova Iorque: The New Press.

O'Neill, P., \& Wilson, M. (Eds.) (2010). Curating and the Educational Turn. Londres: Open Editions.

Paskaleva, K. (2013). Smart cities: A nexus for open innovation?. In M. Deakin (Ed.), Smart Cities: Governing, Modelling and Analysing the Transition. Londres: Routledge.

Remesar, A. (2005). Urban Regeneration: A Challenge for Public Art. Barcelona: Universitat de Barcelona.

Weibel, P. (2013). Globalization and Contemporary Art. In $\mathrm{H}$. Belting, A. Buddensieg \& P. Weibel (Eds.) The Global Contemporary and the Rise of New Art Worlds. Cambridge: The MIT Press.

Zukin, S. (1991). Landscapes of Power: From Detroit to Disney World. Berkeley and Los Angeles: University of California Press.

Catarina Valente (catarina.m.valente@gmail.com). Universidade Lusófona de Humanidades e Tecnologias | CICANT - Center for Research in Applied Communication, Culture, and New Technologies. Campo Grande 376, 1749-024 Lisboa.

Helena Elias (hc.elias@gmail.com). Faculdade de Belas-Artes da Universidade de Lisboa, VICARTE - Glass and Ceramic for the Arts. Largo da Academia Nacional de Belas Artes 4, 1249-058 Lisboa. 